\title{
Research the quality of the caprolon turning with ceramic cutting tools
}

\author{
Oleg Erenkov ${ }^{1, *}$, Alexander Ivakhnenko ${ }^{2}$, and Victor Protasev ${ }^{3}$ \\ ${ }^{1}$ Pacific National University, 680035 Khabarovsk, Russia \\ ${ }^{2}$ South-West State University, 305040 Kursk, Russia \\ ${ }^{3}$ Tula State University, 300041 Tula, Russia
}

\begin{abstract}
The aim of this study is the comparative analysis of caprolon turning with replaceable polyhedral plates made from different materials namely one plate made from wolfram and cobalt alloy VC8 another from ceramic material tungsten free carbide KNT16. The basis of the experimental setup is laboratory research stand STD.201-2 which is used to study the technological system dynamics and the cutting forces registration at turning. The stand functionally consists of the head-tool holder, the interface unit, the sensors connecting module and PC. It is experimentally proved that caprolon turning both with the VC8 alloy cutting plate and the plate made from ceramic material KNT16 is a stable process. This is evidenced by the slight changes values of cutting force main component wherein the range of changes in the case of turning with the ceramic plate is smaller in comparison with the turning option with wolfram and cobalt alloy plate for the selected processing mode.
\end{abstract}

\section{Introduction}

The surface layer condition for a component made of polymer material after machining is evaluated by the physic mechanical properties of these materials and also geometric characteristics of the machined surface. The main geometric characteristics of the surface of a turned component are roughness of shape accuracy.

An increase in roughness and the indices of surface shape deviation for a component from roundness, cylindricity, and rectilinearity arises during machining normally due to a high level of vibrations of the engineering lathe-attachment-tool-component system, unevenness and deformation of the machined material, nonuniformity of machining tolerances.

Turning of polymer materials on the basis of traditional engineering solutions does not in all cases provide the required level of geometric characteristics for a machined surface, since the properties of these materials differ markedly from those of traditional structural materials (steel, cast iron, other alloys).

The correct choice of cutting tool material and a given power parameters in the treatment process is one of the technical solutions, the implementation of which will improve the quality of production of products from polymeric composite materials as well as lowering their cost. The cutting tools on the base of so-called "hard" alloys VC6 and VC8 traditionally are used for the treatment of polymeric composite materials, including the caprolon. At the present time the ceramic cutting tool is actively used for the processing of metal materials and alloys $[1,2]$. Cutting ceramics are characterized by high hardness, including heating, wear resistance, chemical inertness to most metals during the cutting process. The complex of these properties ceramic is significantly superior to conventional cutting tool materials such as high speed steel and hard alloys $[3,4,5]$.

The comparative analysis of the turning of caprolon with the use of the replaceable multifaceted plates made of different material is the aim of the study in this work.

The scientific novelty of the work consists in the obtained results proving the possibility and expediency of using a ceramic tool based on titanium carbonitride with additives of nickel and molybdenum for turning the caprolon, as evidenced by the values of the oscillation of the cutting force and the character of chip formation.

\section{The methodology of the experimental studies}

Caprolon was chosen as a study material. Caprolon is the structural polymer widely used in engineering because of its antifriction properties, wear resistance, high mechanical strength and good ability in cutting processes. The experimental setup scheme is presented on Figure 1.The basis of the experimental setup is a laboratory research stand STD.201-2, which is used to study the dynamics of the technological system machinefixture - tool - work piece and registering cutting forces at turning. Functionally the stand consists of a head-tool holder, the interface module connection of sensors, a personal computer. The laboratory stand measurements range of dynamic loads is from 0 to $15000 \mathrm{~N}$. The most important component of the cutting force $P_{\mathrm{z}}$ was chosen

\footnotetext{
* Corresponding author: Erenkov@list.ru
} 
for the comparative analysis of the turning process which determines the quality and performance of the of turning process in generally [6].

The composite cutters were used for turning. The cutters are equipped by many-sided replaceable plates made from different tool materials. One plate made from hard alloy VC8 and another plate from ceramic material KNT16 which is a tungsten free alloy. Alloy KNT16 produced by $\mathrm{OOO}$ Virial (Russia, St. Petersburg) and has the following chemical composition: titanium carbonitride - 74\%, nickel - $19.5 \%$, molybdenum - $6.5 \%$.

The selected plates are used for turning of hard and churlish materials which include caprolon. Turning of experimental specimens was carried in a universal turning-screw cutting lathe $16 \mathrm{~K} 20 \mathrm{~F} 3 \mathrm{~S} 47$. The geometric parameters and materials of the cutting tool, and also the cutting and feed rates were adopted on the basis of previous studies [6] and kept constant during this series of experiments.

Evaluation of shape deviation for machined component surfaces was performed using a digital measuring unit Rondcom $41 \mathrm{C}$ for such indices as noncylindricity (including non-rectilinearity) of the generating line, and non-roundness.

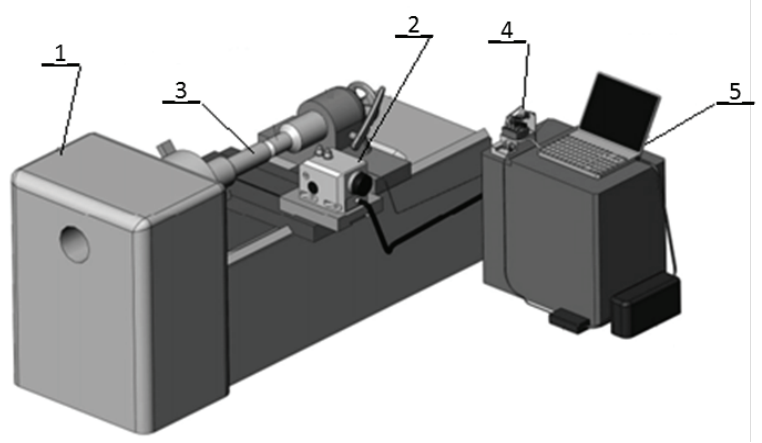

Fig. 1. Experimental set-up:1 - lathe; 2 - head of the tool holder; 3 - work-peace; 4 - the interface unit; 5 - PC.

Component surface roughness was monitored by means of a TR 200 profilometer. As input parameters for surface roughness according to GOST 2789-73 the average deviations were selected for profile $R_{\mathrm{a}}$, height of profile unevenness for ten points $R_{\mathrm{z}}$, greatest height of profile unevenness $R_{\max }$, average step of profile unevenness $S_{\mathrm{m}}$. In addition, in accordance with the international standard ISO 4288 the following surface roughness parameters were determined: distance from the tip of the greatest projection of the profile to the central line $R_{\mathrm{p}}$; distance from the bottom of the greatest depression of the profile to the central line $\mathrm{R}_{\mathrm{m}}$; profile asymmetry $S_{\mathrm{k}}$. According to conditions of ISO 4288, the profile with favorable values of parameter $S_{\mathrm{k}}$ has a clear high peaks, that differ from the average value. A surface with negative values of parameter $S_{\mathrm{k}}$ has clear deep depressions in a smooth profile plateau. In less clear cases, parameter $S_{\mathrm{k}}$ approaches zero. If $S_{\mathrm{k}}>1.5$, then this means that the component surface does not have a simple shape, and it is probably impossible to characterize surface layer quality adequately according to parameters $R_{\mathrm{a}}$ and $R_{z}$.
The research of caprolon chip structure obtained at different variants of turning was carried out with an electron microscope Primo Star.

Thus, experimental studies contained the following types of research such as turning blanks by researched plates at the selected cutting conditions, the registration of the cutting forces, chip selection and study its structure, analysis of the results.

\section{Experimental study and discussion of results}

The results of experimental studies on turning caprolon work pieces by cutting tools made from VC8and KNT16 alloys are graphically showed on Figure 2. Analysis of the presented data allows us to conclude that for all variants of turning the change of cutting force $P_{\mathrm{z}}$ occurs in small intervals. The maximum and minimum values of cutting force $P_{\mathrm{z}}$ investigated at different treatment options are summarized in Table 1. As follows from the data in Table 1 the overall range of the cutting force $P_{\mathrm{z}}$ values variation is from 2.6 to $5.7 \%$. Such assessment is compelling evidence that the process of caprolon pieces turning by selected plates under the above cutting parameters is stable. The cutting process stability in turn is a necessary condition for obtaining the high quality of the machined work piece surface [7].

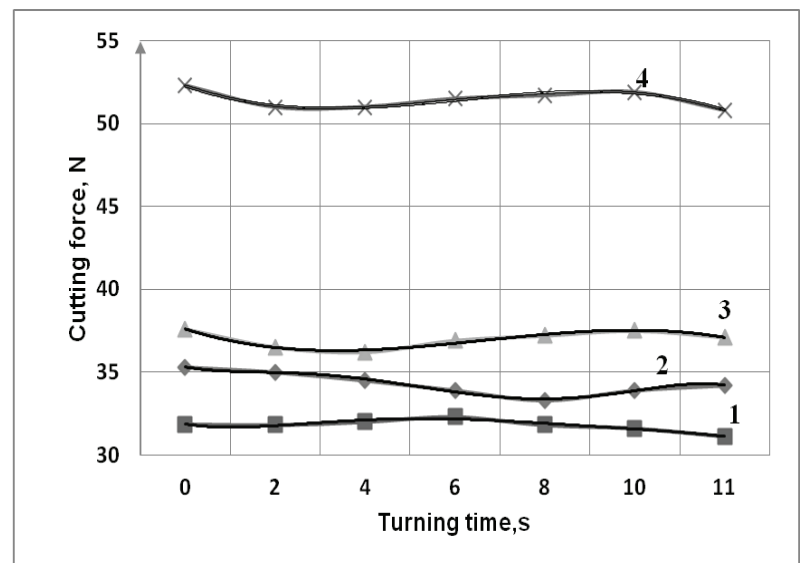

Fig. 2. Cutting force for turning caprolon $P_{\mathrm{z}}: 1-\mathrm{KNT} 16$ plate, $V=160 \mathrm{~m} / \mathrm{min} ; 2-\mathrm{VC} 8$ plate, $V=160 \mathrm{~m} / \mathrm{min}$; VC8 plate 3 , $V=300 \mathrm{~m} / \mathrm{min} ; 4-$ KNT16 plate, $V=300 \mathrm{~m} / \mathrm{min}$.

Table 1. The values of cutting force in turning caprolon.

\begin{tabular}{|c|c|c|c|}
\hline \multirow{2}{*}{$\begin{array}{l}\text { Cutting } \\
\text { tool } \\
\text { material }\end{array}$} & \multirow{2}{*}{$\begin{array}{c}\text { Cutting } \\
\text { speed, } \\
V, \\
\mathrm{~m} / \mathrm{min}\end{array}$} & \multicolumn{2}{|c|}{ Cutting force $P_{\mathrm{z}}, N$} \\
\hline & & Minimum value & $\begin{array}{l}\text { Maximum } \\
\text { value }\end{array}$ \\
\hline \multirow{2}{*}{ VC8 } & 160 & 33,3 & 35,3 \\
\hline & 300 & 36,2 & 37,2 \\
\hline \multirow{2}{*}{ KNT16 } & 160 & 50,6 & 51,9 \\
\hline & 300 & 31,3 & 32,3 \\
\hline
\end{tabular}

The highest values of cutting force $P_{z}$ are observed when caprolon is turning by ceramic plate at cutting speed $300 \mathrm{~m} / \mathrm{min}$. This effect can be explained by the fact that with an increase of turning speed from 160 to $300 \mathrm{~m} / \mathrm{min}$ cutting temperature increase occurs in the 
cutting zone [8]. Tungsten free KNT16 solid alloy has a lower thermal conductivity as compared with the VC carbide and therefore the thermal load caused by the temperature increase in the cutting zone, accumulates mostly in the surface layer of work piece material.

The material becomes more viscous and its destruction occurs by plastic deformation. At the same time respectively the specific work of cutting is increased. The cutting specific work is spent on cutting layer separation and the formation of the chip by means of shear stresses which are the reason for the increase of the cutting force $P_{\mathrm{z}}$. This assumption is confirmed by electron micrographs of caprolon chips presented on Fig. 3 and Fig. 4.

The analysis of chip micrographs showed that the nature of the chip formation at caprolon turning with the specified speeds for the two plates is practically the same. This is evidenced by the fact of the identical type continuous shearing chip formation also the nature of the shear elements regularity distribution $o$ and their geometric parameters.

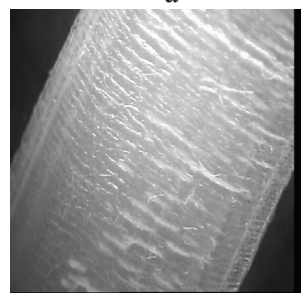

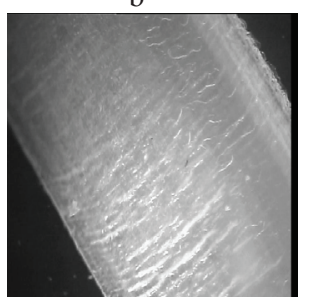

Fig. 3. Caprolon chips obtained by turning at cutting speed of 150 m / min: a - VK8 alloy plate; b - KNT16 alloy plate.

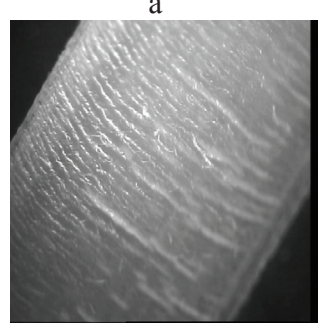

$\mathrm{b}$

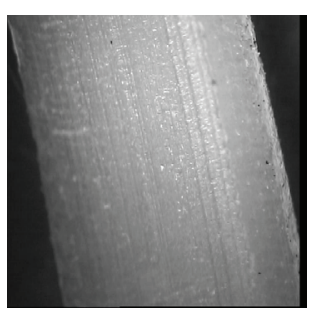

Fig. 4. Chips caprolon obtained by turning at cutting speed of $300 \mathrm{~m} / \mathrm{min}$ : a - VK8 alloy plate; b - KNT16 alloy plate.

An exception is the option of caprolon turning with KNT16 alloy plate at a speed of $300 \mathrm{~m} / \mathrm{min}$. The shear elements of the chips have so small geometric parameters that chips can surely be attributed to the continuous drain. The continuous drain chip forming during caprolon turning continuous also shows the stability of the cutting process and ensure high quality of the machined work piece surface [6].

Numerical values of the test roughness parameters, provided in Table 2, confirm that use of KNT16 alloy plate makes it possible to obtain subsequently a higher quality component surface layer compared with the version of traditional turning with VC8 alloy blade. Here the value of parameter $S_{\mathrm{k}}$ confirms the validity of evaluating roughness according to known parameters $R_{\mathrm{a}}$ and $R_{\mathrm{z}}$.
Table 2. The roughness values of caprolon treated surface.

\begin{tabular}{|c|c|c|c|c|c|c|}
\hline Machining & \multicolumn{6}{|c|}{ Roughness parameters, $\mu \mathrm{m}$} \\
\cline { 2 - 7 } $\begin{array}{c}\text { type (at a } \\
\text { speed } \\
300 \mathrm{~m} / \mathrm{min} \text { ) }\end{array}$ & $R_{\mathrm{a}}$ & $R_{\mathrm{z}}$ & $R_{\mathrm{p}}$ & $R_{\mathrm{m}}$ & $S_{\mathrm{m}}$ & $S_{\mathrm{k}}$ \\
\hline $\begin{array}{c}\text { Turning } \\
\text { with } \\
\text { KNT16 } \\
\text { alloy }\end{array}$ & 2.5 & 7.37 & 4.17 & 5.63 & 0.15 & -0.8 \\
\hline $\begin{array}{c}\text { Turning } \\
\text { with VC8 } \\
\text { alloy }\end{array}$ & 6.6 & 20.2 & 14.8 & 23.1 & 0.5 & -0.6 \\
\hline
\end{tabular}

The deviations of component surface shape such as roundness, cylindricity, and rectilinearity were evaluated with the aim of more detailed comparative analysis. The obtained parameters are presented correspondingly in Figs. 5, 6, and 7.
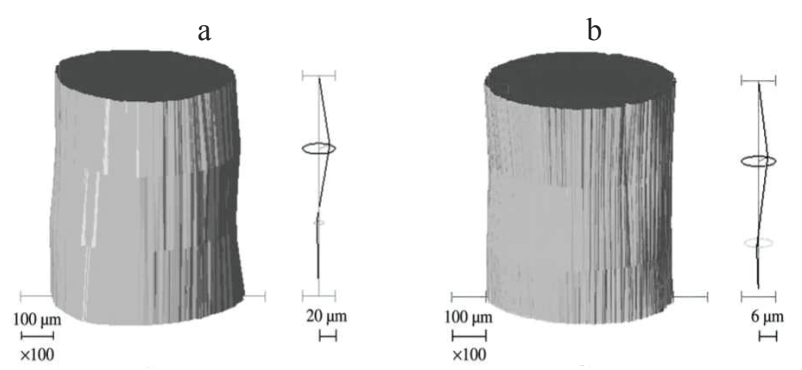

Fig. 5. Deviations from cylindricity after caprolon machining: a) VC8 alloy plate; b) KNT16 alloy plate. a

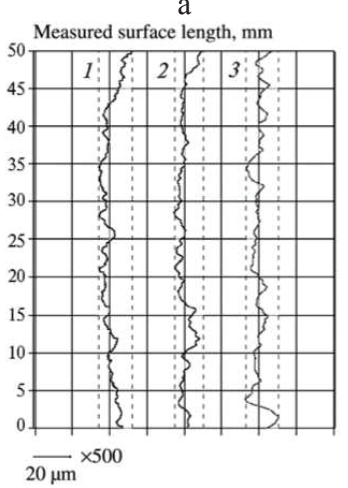

b

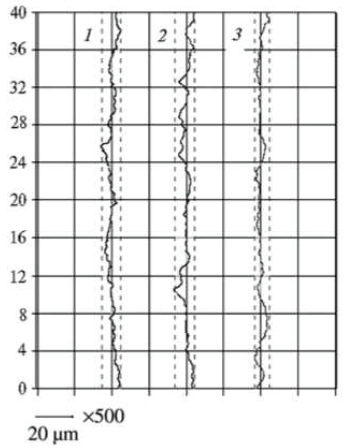

Fig. 6. Deviations from generatrix rectilinearity after caprolon machining: a) VC8 alloy plate; b) KNT16 alloy plate.
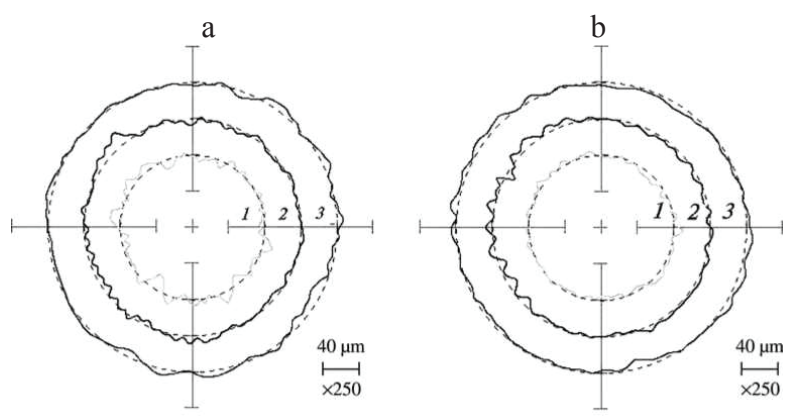

Fig. 7. Deviations from roundness after caprolon machining: a) VC8 alloy plate; b) KNT16 alloy plate. 
According to data for non-cylindricity the caprolon turning with KNT16 alloy plate leads to a reduction in non-cylindricity by approximately more than three times. For example, whereas in the case of caprolon turning with VC8 alloy blade the maximum deviation from cylindricity is $20 \mu \mathrm{m}$, after using the KNT16 alloy plate this deviation does not exceed $6 \mu \mathrm{m}$ (Fig. 5).

Values of component generatrix non-rectilinearity obtained with the test versions of machining have very little difference and for example $28 \mu \mathrm{m}$ at caprolon turning with VC8 alloy blade and $15 \mu \mathrm{m}$ after turning with the KNT16 alloy plate (see Fig. 6).

On the basis of the data obtained (see Fig. 7) for the deviation of component roundness it has been established that use KNT16 alloy plate for caprolon turning promotes some reduction in deviation from roundness. After caprolon turning by the VC8 alloy blade the deviation from roundness is $21 \mu \mathrm{m}$ and after treatment with KNT16 alloy plate it is $19 \mu \mathrm{m}$.

\section{Results of production tests}

We consider the results of production tests for sliding bearing supports made from caprolon and installed in a screw feeder device drive shaft bearing unit for rubber technology production components.

The aim of the test is to study the effect of machined surface quality for bearing supports made of caprolon on the operating efficiency of a bearing unit for this device.

Two sliding supports were tested in succession. The seating surface of support of No.1 was machined by the cutting the KNT16 alloy plate and turning of support No. 2 the billet was made by VC8 alloy blade. After installing bearings within a block for each support made of caprolon they were operated for 120 hours after which vibration diagnostics were performed.
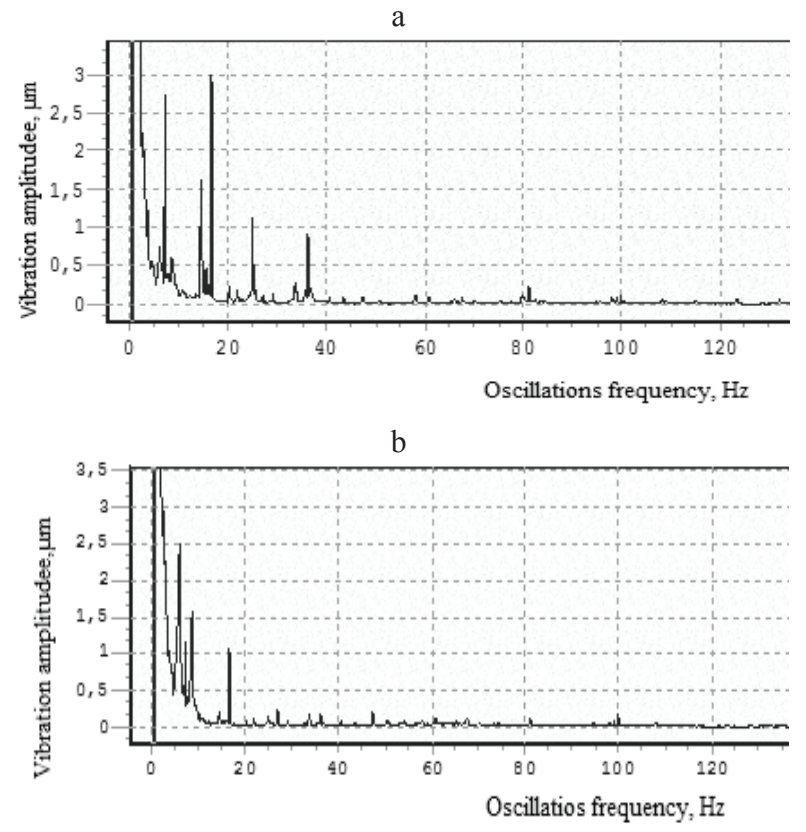

Fig. 8. Vibration amplitude: a - support No.1; b - support No.2.
Vibration diagnostics of bearings was carried out according to a standard [9] using the SD-21 instrument for vibration values control. The output estimates of support operating efficiency were vibration amplitude $A$, $\mu \mathrm{m}$; vibration speed of oscillations, $V, \mathrm{~mm} / \mathrm{sec}$; vibration acceleration of oscillations, $a, \mathrm{~mm} / \mathrm{sec}^{2}$.

Analysis of data obtained shows that the use of support No.1 manufactured by caprolon turning with KNT16 alloy plate provides more efficient operation of a bearing assembly and the device as a whole. This is indicated by the lower values of recorded vibration parameters compared with similar values for support No.2 (see Fig. 8).

\section{Conclusions}

So the following conclusions can be formulated on the basis of the research results:

- experimentally proved that turning process is stable both at caprolon cutting with VC8 alloy blade and caprolon cutting with plate from ceramic material KNT16. The turning process stability is confirmed by the slight values changes of cutting force main component $P_{\mathrm{z}}$ the while the change range in the case of caprolon turning with ceramic plate is smaller in comparison with the change range at caprolon turning with VC8 alloy blade for the selected processing modes; - established experimentally that caprolon machining is advisable to use many-sided replaceable plates made from KNT16 while at a speed of cut of $300 \mathrm{~m} / \mathrm{min}$ the use of the ceramic plate is more preferable compared with a plate from VC8 alloy as evidenced by the type of received chips;

- the use of many-sided replaceable plates for polymeric materials turning allows expanding the range of instruments used and increasing the efficiency of the overall turning process;

- the caprolon turning with cutter equipped with KNT16 alloy plate leads to a marked reduction in such indices for surface shape deviation, as non-roundness and noncylindricity, and there is almost no effect on nonrectilinearity;

- results of production tests entirely confirm the expediency of using caprolon turning by ceramic cutting tools made since realization of this approach finally made it possible to provide a reduction in the vibration level of industrial devices.

\section{References}

1. B.N. Arzamasov, Materials Science (M.: Publishing house of the Moscow Higher Technical School Bauman, 2001)

2. F. Klocke, Manufacturing Processes 1: Cutting (Berlin: Springer-Verlag., 2011)

3. A.S. Vereshchaka, Cutting materials (M.: Higher School Publishing., 2009)

4. G. Smith, Cutting Tool Technology (Industrial Handbook, London: Springer-Verlag London Limited, 2008) 
5. P. Davim, Machining of Hard Materials (London: Springer-Verlag London Limited, 2011)

6. O.Yu. Erenkov, S.A. Kovalchuk, A.V. Gavrilova, Combined method of plastic work piece machining based on a pretreatment mechanical down, Rare metals, Vol.26, Spec. Issue, pp.20-24 (2007)

7. O.Yu. Erenkov, A.G. Ivakhnenko, M.V. Radchenko, Oscillatory process of production systems during turning of caprolon blanks, Chemical and Petroleum Engineering, Vol. 49, Issue 5-6, pp. $411-417$ (2013)

8. O.Yu. Erenkov, E.G. Kalita, E.O. Ivakhnenko, Study of the Effect of Cutting Regimes on Chip Formation, Chemical and Petroleum Engineering, Vol.50, Issue 3-4, pp. 273-276 (2014)

9. GOST R ISO 7919-3-99. Monitoring the State of Machines from the Results of Measuring Vibrations on Rotating Shafts, Izd. Standartov, Moscow (1999) 